\title{
Incubator temperature control: effects on the very low birthweight infant
}

\author{
D A DUCKER, A J LYON, R ROSS RUSSELl, C A BASS, AND N McINTOSH \\ Department of Child Health, St George's Hospital Medical School, London
}

SUMmaRY We studied temperature stability in 22 infants of birthweight less than $1500 \mathrm{~g}$ in the first four days of life. Infants were nursed in incubators using either air mode control or skin temperature servo control. Data were collected continuously using a computer linked monitoring system. Skin temperature control resulted in a less stable thermal environment than air mode control. Increased thermal stability in the incubator on air mode control may well be beneficial, particularly to sick, very low birthweight infants.

Control of environmental temperature is important for the survival of very low birthweight infants. Cold stress leads not only to increased mortality ${ }^{1}$ but also to adverse effects on weight gain and growth in length and head circumference. ${ }^{2} 3$ High environmental temperatures have also been associated with increased mortality and morbidity in these infants. ${ }^{4}$ In particular, high and fluctuating temperatures have been associated with an increased incidence of apnoea. ${ }^{5}$ Very low birthweight infants should be nursed in a stable environment at the optimal ambient temperature needed to minimise metabolic stress. ${ }^{67}$ Thermo-neutral temperatures have been reported for different birthweights and gestational ages, ${ }^{89}$ and these can be used to set the incubator temperature (air mode control).

In the very immature infant, the thermo-neutral range is narrow. ${ }^{10}$ Factors other than environmental temperature, such as temperature gradient across the incubator walls, humidity, and air velocity within the incubator will affect heat loss. To overcome these problems the infant's own temperature (sensed by a thermistor taped to the skin) has been used to control the environmental temperature (servo mode). This study aimed to compare the two methods of temperature control in very low birthweight infants undergoing routine intensive care.

\section{Patients and methods}

In the intensive care unit at this hospital, the policy is to nurse very low birthweight infants naked and covered by a single layer of bubble plastic in a humidified incubator. During the study no changes were made in any nursing or medical policy as we were interested in the thermal stresses on these immature infants during day to day intensive care.

Twenty two consecutive infants of birthweight less than $1500 \mathrm{~g}$ were studied. The first 12 (median gestation 28 , range 24 to 35 weeks; median birthweight 980 , range 520 to $1360 \mathrm{~g}$ ) were nursed in servo controlled incubators and the subsequent 10 (median gestation 28 , range 24 to 31 weeks; median birthweight 1000 , range 590 to $1460 \mathrm{~g}$ ) in incubators controlled by air mode.

Data were obtained using a computer linked patient monitoring system which has been developed at this hospital. ${ }^{11}$ The statistics package designed to extract and analyse data collected by the patient monitoring system was used to produce the histograms and other results for this study. The computer monitor was situated outside the nursery and data was not readily available to the staff. Decisions on temperature control were not therefore influenced by the study. The data from four channels is reported here.

Abdominal skin and toe temperatures, as measures of central and peripheral temperatures respectively, were measured via Simonsen and Weel 8000 series monitors. Continuous rectal temperatures were not recorded in the unit because of the problems associated with rectal probes in very small neonates. Ambient temperature and humidity were measured by a combined probe placed near the 
infant's head. This device was developed independently and used a thermistor for temperature measurement mounted alongside a Viasala adsorption electro humidity sensor.

No efforts were made to control humidity other than keeping water in the humidifier tank of the incubator. All infants underwent blood pressure and electrocardiographic monitoring. Changes in blood pressure together with changes in central-peripheral temperature difference indicative of hypovolaemia were treated early in both groups with infusion of blood or colloid. The infants were entered into the study on transfer to a humidified Vickers 79 incubator with proportional servo control and were all studied for at least 48 hours.


\section{Results}

The results are derived from more than 700 hours of continuous monitoring in each of the two groups of patients. Figure 1 shows the proportion of time that each of the three measured temperatures were held within $0.5^{\circ} \mathrm{C}$ intervals between $33^{\circ} \mathrm{C}$ and $39.5^{\circ} \mathrm{C}$ together with the mean and standard deviation. These are average values for all the infants in each group taken over the first four days of life. Figures 2 and 3 are typical computer graphs of similar infants in incubators controlled by servo and air mode respectively. These graphs show the great variability of both ambient and peripheral temperature in the servo controlled group. In these infants it can also
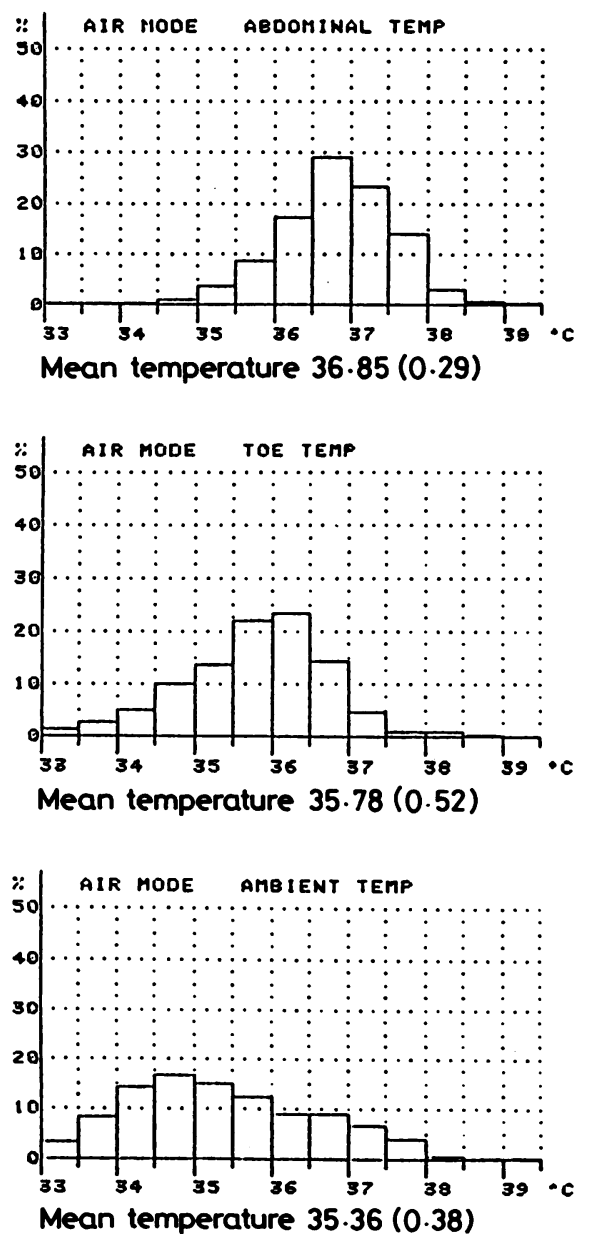

Fig. 1 Computer histograms showing proportion of time as a percentage.

Each temperature was held within $0.5^{\circ} \mathrm{C}$ bands for abdominal, toc and ambient temperature for each of these two study groups. 


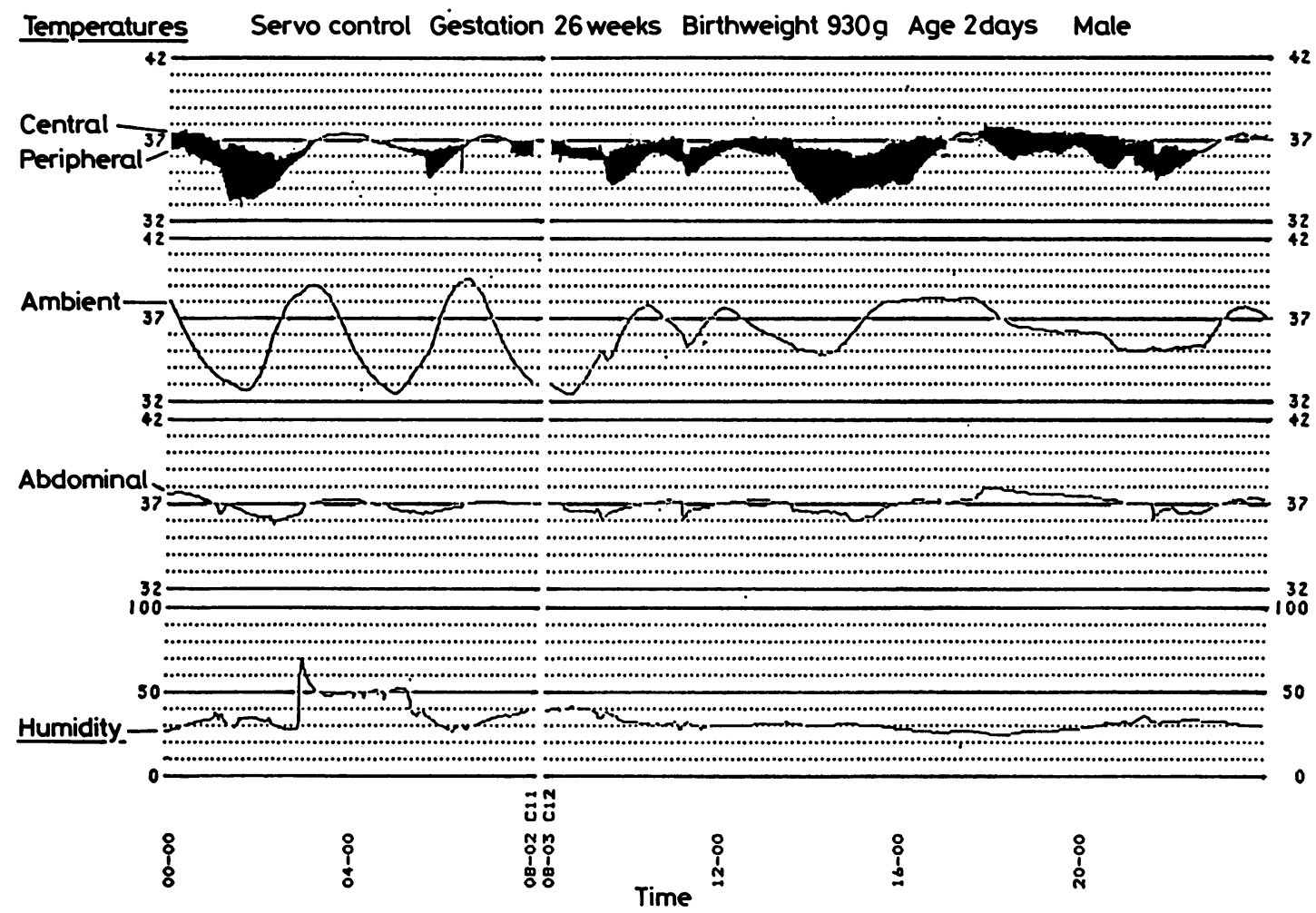

Fig. 2 Typical 24 hour graph showing fluctuation of central-peripheral temperature with ambient temperature in an infant using servo control. Note the stable abdominal temperature.

be seen that any decrease in abdominal skin temperature, and therefore activation of the incubator heat control, occurred only after there had been an appreciable drop in toe temperature. This delay was seen in all the infants nursed in servo controlled incubators. There was a corresponding delay in switching off the heater as the abdominal skin temperature increased, resulting in a small overshoot of the infant's temperature above the set value. The peripheral temperature, as measured by the toe probe, varied in the same direction as, and as rapidly as, the changes in ambient temperature.

For each infant, the variance of the mean daily central-peripheral temperature difference was used as a measure of temperature stability. Figure 4 shows for each group the mean (SD) variance of the central-peripheral temperature difference plotted against age for the first four postnatal days. It can be seen that in servo controlled incubators there was wide fluctuation in the infant's central-peripheral temperature difference during the first three days of life. In the air mode incubators there was little variability in this temperature difference, suggesting that the infants were thermally more stable. With increasing age, the variance decreased in both groups suggesting a maturation of temperature control.

The sudden increases in humidity seen in Figs. 2 and 3 were due to water being added to the incubator reservoir. In some cases this was routine topping up. At other times warm water was added in an attempt to raise the infant's temperature quickly, to recover from a drop in temperature usually caused by heat lost from the incubator during medical procedures. The significant changes between 12.00 and about 20.00 in the patient illustrated in Fig. 3 are explained by the nursing comment C23 which states 'Gone off. Just bagged and reintubated'. Throughout the study of servo control the humidity in the incubators was mean (SD) $46 \%(6 \%)$ while in the air mode study it was $53 \%(7 \%)$. The reason for this difference is not clear, although it may reflect an increased awareness by the nursing staff in the later parts of this study of the importance of humidity in the very low birthweight infant. 


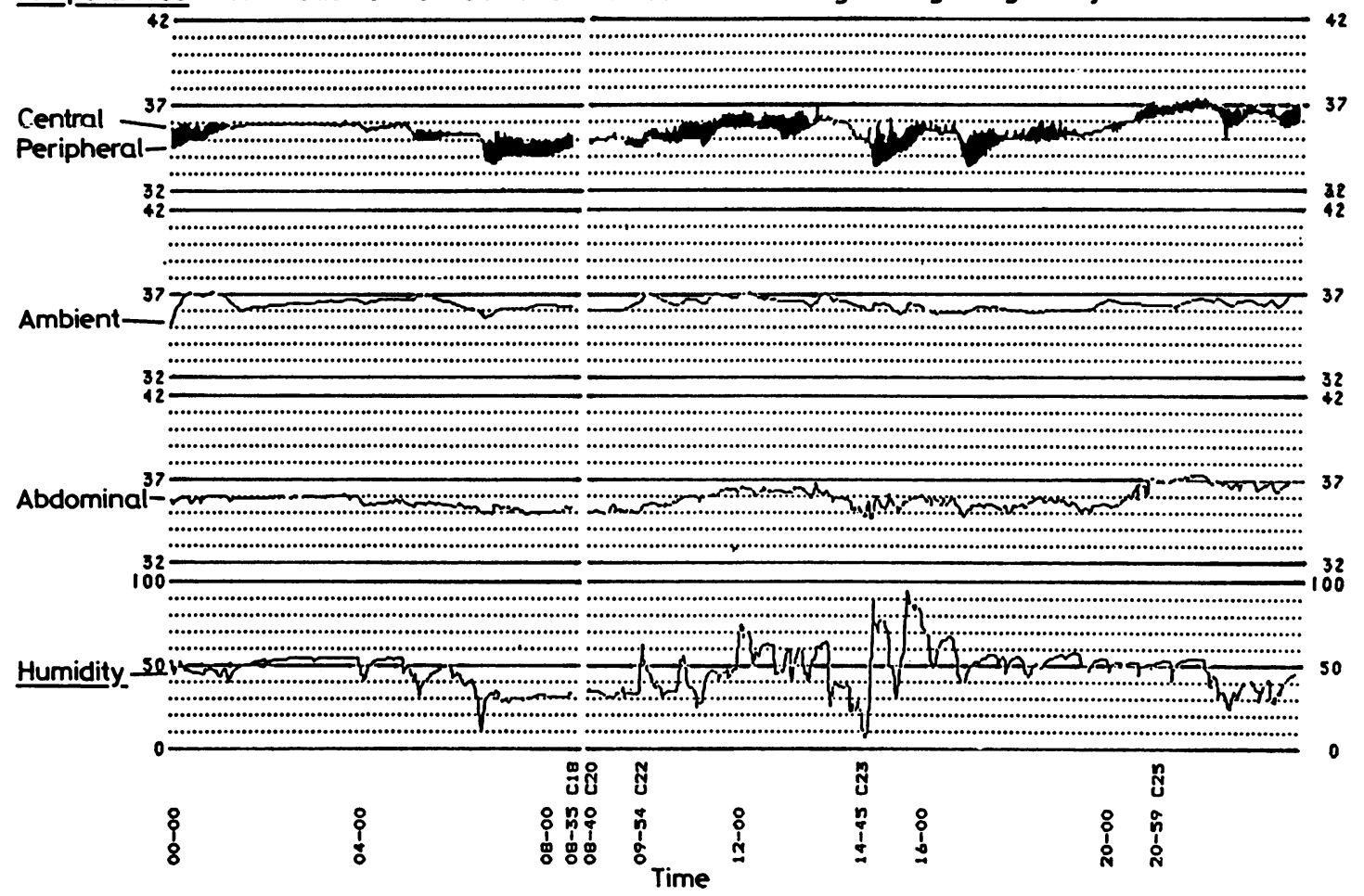

Fig. 3 Typical 24 hour graph in an infant using air mode control.

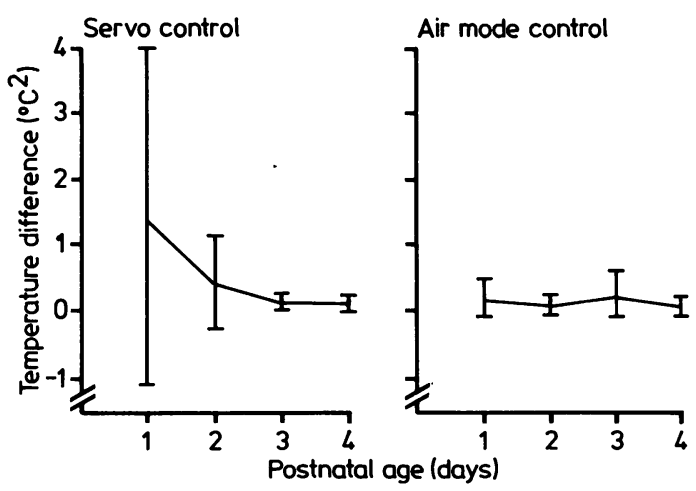

Fig. 4 Variance (mean $(S D)$ ) of central peripheral temperature difference.

\section{Temperature probe problems.}

(a) The abdominal skin probe was sometimes found off or only partially applied to the skin. As the environmental temperature was usually below the infant's skin temperature, the lower probe tempera- ture activated the heater and resulted in appreciable overheating before being noticed by the staff.

(b) In several cases it was noted that the abdominal skin temperature registered by the probe was higher than the rectal temperature recorded four hourly with a mercury thermometer. This was thought to be due to the adhesive pad covering the abdominal probe preventing evaporative heat losses from this area of skin and hence artificially raising the temperature of this site. The result was that the infant was nursed in a suboptimal environmental temperature. The problem was resolved by increasing the humidity in the incubator and reducing the evaporative heat losses from all areas of skin.

(c) False high abdominal skin temperature readings were also obtained whenever the infant was allowed to lie on the probe. Despite an awareness by the nursing staff, this problem occurred frequently.

(d) Covering the baby with clothes or blankets resulted in the incubator cooling as the insulation maintained the abdominal skin temperature. When the infant was uncovered for any procedure, however, rapid cooling occurred before the incubator could respond. 
These problems with the temperature probe in the servo controlled system resulted in inappropriate environmental temperature changes.

\section{Discussion}

The use of a computer based monitoring system has allowed the continuous collection of data and analysis of the way in which several variables alter in relation to one another. Previously, information on the temperature control of sick very low birthweight infants undergoing intensive care has been difficult to obtain because of the rapid changes occurring during the necessary medical and nursing procedures.

Very low birthweight infants do not always show an increase in oxygen consumption at a temperature outside the neutral range, but react with a change in body temperature. ${ }^{9}$ The use of oxygen consumption as a measure of thermal stress can be misleading and Sauer et al $l^{9}$ have redefined the neutral thermal environment of very low birthweight infants as the ambient temperature at which the core temperature of the infant at rest is between 36.7 and $37.3^{\circ} \mathrm{C}$ and the core and mean skin temperatures are changing less than 0.2 and $0.3^{\circ} \mathrm{C}$ per hour respectively. For this study we have defined thermal stress as any widening of the central-peripheral temperature difference which was not due to hypovolaemia. The limited homeothermic ability was shown in this study by the way in which changes in peripheral skin temperature closely followed ambient temperature. A significant positive correlation between the toe and ambient temperatures in the servo control group has been reported previously. ${ }^{12}$ The results suggest that in the first few days of life, sick very low birthweight infants in servo controlled incubators are in a less stable thermal condition than those in air mode incubators.

The abdominal skin is the site most commonly used for the servo controlled temperature probe. This study shows that changes in abdominal skin temperature occur considerably later than the temperature changes in a more peripheral skin site, and therefore the incubator heater responds only after some delay, when appreciable cooling has already occurred. Delay in switching off the heater resulted in an overshoot of the infant's temperature above the set value. Servo control therefore effectively maintained the reference temperature within a narrow range but did so by exposing the infant to both heat and cold stress in an unstable thermal environment. The increased morbidity and mortality in this situation are well recognised. ${ }^{5} 131415$

The infants in incubators controlled in air mode had a more stable thermal environment and showed much less variation in the abdominal and toe temperature and also in the central-peripheral temperature difference.

It is likely that increased humidity will result in both lower and more stable environmental temperatures. The higher mean humidity during the air mode study may have been responsible for some of the increased thermal stability seen in this part of the study. The increase in humidity, however, was small and probably does not account for much of the difference to be found between the two groups.

Servo control of infant temperature relies on accurate information from the probe attached to the baby's skin. Several problems with this system have been highlighted and other studies have reported similar findings. ${ }^{16}$ When functioning correctly, however, this study has shown that the use of servo control with the abdominal skin temperature as the reference seems to create further problems for the very low birthweight infant. Using a more peripheral temperature as a reference, for example deltoid skin, may allow a more rapid response of the incubator heater, but the technical problems of keeping the probe attached and not covered by the baby or its clothing would be considerable. A better reference may be the difference between a central and a peripheral skin temperature. In healthy preterm neonates servo and air mode have been reported to be equally effective and safe in the control of thermal environment. ${ }^{17}$ We have shown that during the first two days of life sick very low birthweight infants undergoing intensive care suffer increased thermal stress when nursed under servo mode. Air mode control, often using incubator temperatures as high as $37^{\circ} \mathrm{C}$, seems to be a better method of temperature control for these infants.

We thank the nurses and medical staff on the Special Care Baby Unit at St George's Hospital, Paul Cartnell of Loughborough University who made the humidity measuring device, and Jean Felton who typed the manuscript.

\footnotetext{
References

'Silverman WA, Fertig JW, Berger AP. The influence of the thermal environment upon the survival of newly born premature infants. Pediatrics 1958;22:876-86.

2 Glass L, Silverman WA, Sinclair JC. Effect of the thermal environment on cold resistance and growth of small infants after the first week of life. Pediatrics 1968;41:1033-46.

${ }^{3}$ Glass L, Silverman WA, Sinclair JC. Relationship of thermal environment and calorie intake to growth and resting metabolism in the late neonatal period. Biol Neonate 1969;14:324-40.

4 Yashiro K, Adams FH, Emmanoulides GC, Mickey MR. Preliminary studies on the thermal environment of low birthweight infants. J Pediatr 1973;82:991-4.

5 Perlstein PH, Edwards NK, Sutherland JM. Apnoea in premature infants and incubator air temperature changes. $N$ Engl $J$ Med 1970;282:461-6.

${ }^{6}$ Hey EN. Thermal neutrality. Br Med Bull 1975;31:69-74.
} 
${ }^{7}$ Bligh J, Johnson KG. Glossary of terms for thermal physiology. J Appl Physiol 1973:35:941-61.

${ }^{8}$ Hey EN, Katz G. The optimum thermal environment for naked babies. Arch Dis Child 1970;45:328-34.

9 Sauer PJJ, Dane HJ, Visser HKA. New standards for neutral thermal environment of healthy very low birthweight infants in week one of life. Arch Dis Child 1984;59:18-22.

10 Wheldon AE, Hull D. Incubation of very immature infants. Arch Dis Child 1983:58:504-8.

$"$ Bass CA, Smith JS, Ducker DA. The use of a computer linked monitoring system for the continuous collection of physiological and environmental data from neonates undergoing intensive care. In: Rolfe $\mathrm{P}$, ed. Proceedings of the 2nd international conference on fetal and neonatal physiological measurement. London: Butterworth, (In press).

12 Hey E. Temperature regulation in sick infants. In: Tinker $J$, Rapin M, eds. Care of the critically ill patient. New York: Springer-Verlag, 1983:1013-29.

13 Ducker DA, Lyon AJ, Whecler KA, McIntosh N, Bass CA. Temperature variability of very low birthweight infants nursed in servo controlled incubators. In: Rolfe P, ed. Proceedings of the 2nd international conference on fetal and neonatal physiological measurement. London: Butterworth, (In press).

14 Perlstein PH, Edwards NK, Atherton HD, Sutherland JM. Computer assisted newborn intensive care. Pediatrics 1976;57:494-501.

15 Belgaumkar TK, Scott KE. Effects of low humidity on small premature infants in servo controlled incubators. II. Increased severity of apnoea. Biol Neonate 1975;26:348-52.

${ }^{16}$ Hull D. Chellappah G. On keeping babies warm. In: Chiswick ML, ed. Recent advances in perinatal medicine. no. 1. Edinburgh: Churchill Livingstone, 1983:153-68.

17 Bell EF, Bios GR. Air versus skin temperature servo control of infant incubators. J Pediatr 1983;103:954-9.

Correspondence to Dr A Ducker, All Saints Hospital, Chatham, Kent ME4 5NG.

Reccived 19 May 1985. 